Article

\title{
A Divergent Alkyne Diol Directs [2 + 2] Photoreactivity in the Solid State: Cocrystal, Supramolecular Catalysis, and Sublimation Effects
}

\author{
Shalisa M. Oburn ${ }^{\circledR}$, Jay Quentin $₫$ and Leonard R. MacGillivray *(i) \\ Department of Chemistry, University of Iowa, Iowa City, IA 52242, USA \\ * Correspondence: len-macgillivray@uiowa.edu \\ Academic Editor: Linda S. Shimizu \\ Received: 27 July 2019; Accepted: 19 August 2019; Published: 22 August 2019
}

check for

\begin{abstract}
: 2-butyne-1,4-diol (1,4-bd) is used as a divergent ditopic template that directs trans-1,2-bis (n-pyridyl) ethylene $\left(n, n^{\prime}\right.$-bpe, where $n=n^{\prime}=3$ or 4$)$ to undergo an intermolecular [2+2] photodimerization in the solid state. The components of cocrystals $\left[(\mathbf{1}, \mathbf{4}-\mathbf{b d}) \cdot\left(\mathbf{4}, \mathbf{4}^{\prime} \text {-bpe }\right)\right]_{\mathrm{n}}$ and $\left[(\mathbf{1}, \mathbf{4} \text {-bd }) \cdot\left(3,3^{\prime} \text {-bpe }\right)\right]_{n}$ form $1 \mathrm{D}$ hydrogen-bonded polymers with $n, n^{\prime}$-bpe assembled as infinite parallel stacks. The alkenes undergo [2 + 2] photocycloadditions to form $r c t t$-tetrakis ( $n$-pyridyl) cyclobutane (where $n=3$ or 4 ). We demonstrate that the reactive solid involving $4,4^{\prime}$-bpe exhibits supramolecular catalysis.
\end{abstract}

Keywords: supramolecular catalysis; divergent template; solid state; [2 + 2] photocycloaddition

\section{Introduction}

We have recently demonstrated that intermolecular [2 + 2] photodimerizations can be directed using principles of supramolecular catalysis in the solvent-free environment of the solid state. The ditopic hydrogen-bond-donor 4,6-dichloro-resorcinol (4,6-diCl-res) was used in catalytic amounts as a template to achieve a [2 + 2] photodimerization of trans-1,2-bis (4-pyridyl) ethylene $\left(\mathbf{4}, \mathbf{4}^{\prime}\right.$-bpe) [1,2]. Supramolecular catalysis of the photodimerization involving $4, \mathbf{4}^{\prime}$-bpe was also realized using ditopic organoboronic acids as templates [3]. The approach to supramolecular catalysis was performed mechanochemically via vortex grinding [2]. In both cases, the catalysts functioned as convergent ditopic receptors with reactivity occurring within zero-dimensional (0D), or discrete, hydrogen-bonded structures.

Seminal work of Toda has reported on the reactivity properties of host-guest complexes formed with the divergent ditopic host 1,1,6,6-tetraphenyl-hexa-2,4-diyne-1,6-diol (1,6-diol). The diol interacted with chalcones to generate photoactive hydrogen-bonded solids [4]. The 1,6-diol assembled the olefins within solid-state cavities supported by the bulky tetraphenyl-substituents of the host. The reactive solids based on 1,6-diol also formed via dry grinding [5]. Moreover, simple shaking of 1:2 and 1:4 solid mixtures of 1,6-diol and the chalcones resulted in up to $90 \%$ photoconversion following UV-irradiation.

Here, we report the ability of 2-butyne-1,4-diol (1,4-bd) - effectively, a minimalist derivative of 1,6-diol-to act as a divergent ditopic template of an intermolecular [2 +2 ] photodimerization in the solid state (Scheme 1). Cocrystallizations of 1,4-bd with trans-1,2-bis ( $n$-pyridyl) ethylene $\left(n, n^{\prime}\right.$-bpe, where $n=n^{\prime}=3$ or 4$)$ generate cocrystals of composition $\left[(\mathbf{1}, \mathbf{4}-\mathbf{b d}) \cdot\left(\mathbf{4}, \mathbf{4}^{\prime} \text {-bpe }\right)\right]_{\mathrm{n}}$ and $\left[(\mathbf{1}, \mathbf{4}-\mathbf{b d}) \cdot\left(3,3^{\prime}-\mathrm{bpe}\right)\right]_{\mathrm{n}}$. The components of the cocrystals form $1 \mathrm{D}$ hydrogen-bonded polymers with olefins that stack into infinite columns. UV-irradiation of each solid generates $r c t t$-tetrakis (n-pyridyl) cyclobutanes $\left(n, n^{\prime}-\right.$ tpcb) stereoselectively. We also reveal $\mathbf{1 , 4 - b d}$ to act as a supramolecular catalyst for the photoreaction involving $4,4^{\prime}$-bpe. 
a)

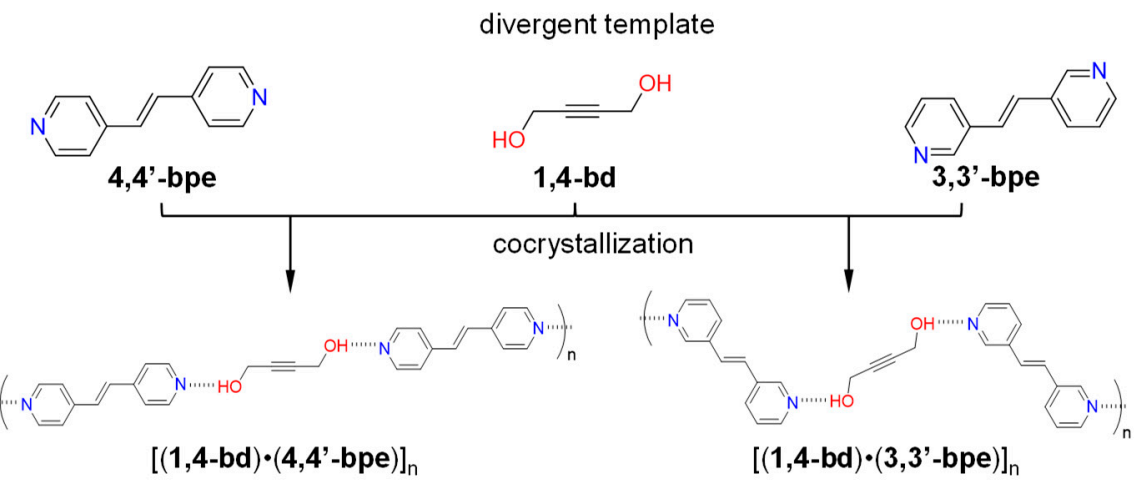

b)

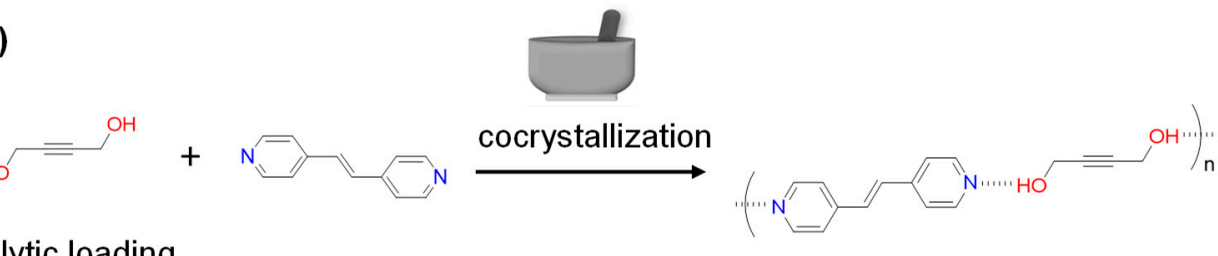

catalytic loading

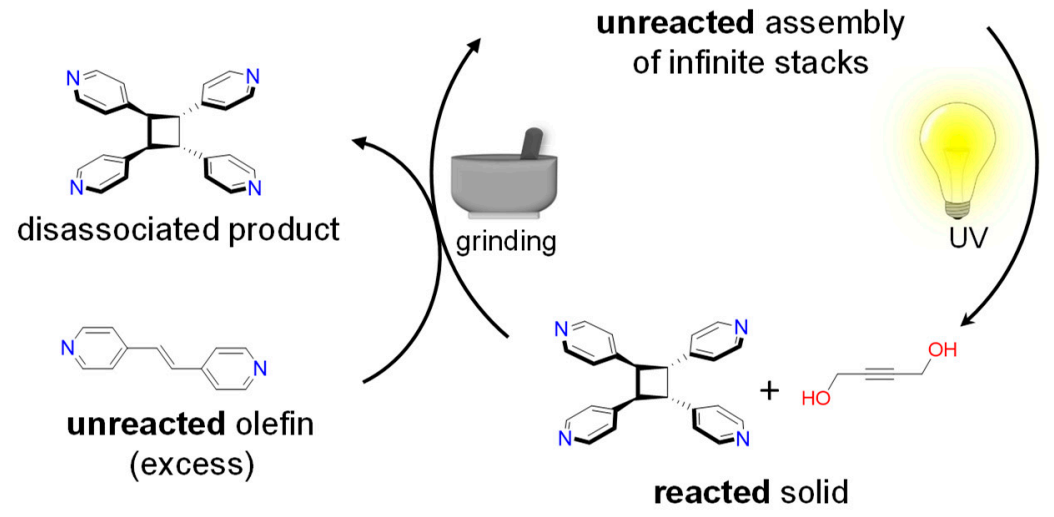

Scheme 1. Photoreactive cocrystals using (a) divergent 1,4-bd and (b) supramolecular catalysis.

\section{Results and Discussion}

\subsection{Photoreactive Cocrystals of $\left[(\mathbf{1}, \mathbf{4}-\mathbf{b d}) \cdot\left(\mathbf{4}, \mathbf{4}^{\prime}-\mathbf{b} \mathbf{p e}\right)\right]_{\mathrm{n}}$}

Cocrystals of composition $\left[(\mathbf{1}, \mathbf{4}-\mathbf{b d}) \cdot\left(\mathbf{4}, \mathbf{4}^{\prime} \text {-bpe }\right)\right]_{n}$ were obtained by combining equimolar solutions of $4,4^{\prime}$-bpe and 1,4-bd in acetonitrile, and allowing the resulting solution to slowly evaporate to yield colorless plate-like crystals suitable for single-crystal $X$-ray diffraction.

The components of $\left[(\mathbf{1}, \mathbf{4}-\mathbf{b d}) \cdot\left(\mathbf{4}, \mathbf{4}^{\prime} \text {-bpe) }\right]_{\mathrm{n}}\right.$ crystallize in the monoclinic space group $P 2_{1} / c$ (Table 1 , Figure 1). The asymmetric unit contains one half each of a molecule of $\mathbf{1}, \mathbf{4}$-bd and $\mathbf{4}, \mathbf{4}^{\prime}$-bpe. The diol and bipyridine interact via $\mathrm{O}-\mathrm{H} \cdots \mathrm{N}$ hydrogen bonds $[\mathrm{O}(1) \cdots \mathrm{N}(2)$ separation $(\AA): 2.792(2)]$ to generate infinite 1D hydrogen-bonded chains that propagate along the crystallographic $c$-axis. The hydroxyl groups of 1,4-bd adopt an anti-conformation with a dihedral angle of nearly $180^{\circ}$. Adjacent $1 \mathrm{D}$ hydrogen-bonded chains are sustained by bifurcating-type $\mathrm{C}-\mathrm{H}$ (pyridine) $\cdots \mathrm{O}$ and $\mathrm{C}-\mathrm{H}($ alkene) $\cdots \mathrm{O}$ forces along the $b$-axis [C...O separations $(\AA)$ : $C(8) \cdots \mathrm{O}(1) 3.43, \mathrm{C}(4) \cdots \mathrm{O}(1) 3.58$ ] such that neighboring $1 \mathrm{D}$ chains lie offset and tilted by $56.4^{\circ}$. The hydrogen-bonded chains pack into segregated $2 \mathrm{D}$ stacks along the $a$-axis. The carbon-carbon double $(\mathrm{C}=\mathrm{C})$ bonds of the stacked olefins are organized parallel and separated by $4.19 \AA$, which conforms to the criteria of Schmidt for a [2+2] photocycloaddition in the solid state [6]. 
Table 1. Crystallographic data for $\left[(1,4-b d) \cdot\left(4,4^{\prime}-\mathbf{b p e}\right)\right]_{\mathrm{n}},\left[(1,4-\mathbf{b d}) \cdot\left(3, \mathbf{3}^{\prime}-\mathbf{b p e}\right)\right]_{\mathrm{n}}$, and $\left(r c t t-3, \mathbf{3}^{\prime}-\mathrm{tpcb}\right) \cdot\left(\mathrm{H}_{2} \mathrm{O}\right)$.

\begin{tabular}{|c|c|c|c|}
\hline Cocrystal/Hydrate & {$\left[(1,4-b d) \cdot\left(4,4^{\prime}-b p e\right)\right]_{n}$} & {$\left[(1,4-b d) \cdot\left(3,3^{\prime}-b p e\right)\right]_{n}$} & $\left(r c t t-3,3^{\prime}-\mathrm{tpcb}\right) \cdot\left(\mathrm{H}_{2} \mathrm{O}\right)$ \\
\hline Formula & $\mathrm{C}_{16} \mathrm{H}_{16} \mathrm{~N}_{2} \mathrm{O}_{2}$ & $\mathrm{C}_{16} \mathrm{H}_{16} \mathrm{~N}_{2} \mathrm{O}_{2}$ & $\mathrm{C}_{24} \mathrm{H}_{22} \mathrm{~N}_{4} \mathrm{O}$ \\
\hline $\begin{array}{l}\text { Formula weight } \\
\qquad\left(\mathrm{g} \cdot \mathrm{mol}^{-1}\right)\end{array}$ & 268.31 & 268.31 & 382.45 \\
\hline Crystal system & Monoclinic & Monoclinic & Triclinic \\
\hline Space group & $P 2_{1} / c$ & $P 2_{1} / n$ & P-1 \\
\hline$a(\AA)$ & $4.1905(4)$ & $10.8899(12)$ & $8.7650(9)$ \\
\hline$b(\AA)$ & $10.9558(11)$ & $4.2077(4)$ & $9.4600(9)$ \\
\hline$c(\AA)$ & $15.8790(16)$ & $16.2118(16)$ & $13.0903(13)$ \\
\hline$\alpha\left(^{\circ}\right)$ & 90 & 90 & $92.879(5)$ \\
\hline$\beta\left({ }^{\circ}\right)$ & $91.420(5)$ & $101.580(5)$ & $94.862(5)$ \\
\hline$\gamma\left({ }^{\circ}\right)$ & 90 & 90 & $112.923(5)$ \\
\hline $\mathrm{Z}$ & 2 & 2 & 2 \\
\hline$V\left(\AA^{3}\right)$ & $728.79(12)$ & $727.73(13)$ & $991.99(17)$ \\
\hline$\rho_{\text {calcd }}\left(\mathrm{g} \cdot \mathrm{cm}^{-3}\right)$ & 1.223 & 1.224 & 1.280 \\
\hline$T(\mathrm{~K})$ & 298 & 298 & 298 \\
\hline$\mu\left(\mathrm{mm}^{-1}\right)$ & 0.082 & 0.082 & 0.081 \\
\hline Reflections collected & 10144 & 9896 & 7864 \\
\hline$F(000)$ & 284 & 284 & 404 \\
\hline Crystal size $\left(\mathrm{mm}^{3}\right)$ & $0.19 \times 0.18 \times 0.05$ & $0.32 \times 0.27 \times 0.13$ & $0.34 \times 0.22 \times 0.07$ \\
\hline Independent reflections & 1320 & 1428 & 4189 \\
\hline Data/restraints/parameters & $1320 / 0 / 92$ & $1428 / 0 / 100$ & $4189 / 0 / 284$ \\
\hline$R_{\text {int }}$ & 0.0257 & 0.0234 & 0.0355 \\
\hline$R_{1}(I \geq 2 \sigma(I))$ & 0.0361 & 0.0356 & 0.0561 \\
\hline$w R\left(F^{2}\right)(I \geq 2 \sigma(I))$ & 0.0880 & 0.0881 & 0.1293 \\
\hline$R_{1}$ (all data) & 0.0538 & 0.0495 & 0.1277 \\
\hline$w R\left(F^{2}\right)$ all data & 0.0996 & 0.0975 & 0.1618 \\
\hline Goodness-of-fit on $F^{2}$ & 1.054 & 1.077 & 1.018 \\
\hline $\begin{array}{c}\text { CCDC deposition } \\
\text { number }\end{array}$ & $1,942,417$ & $1,942,416$ & $1,871,324$ \\
\hline
\end{tabular}

(a)

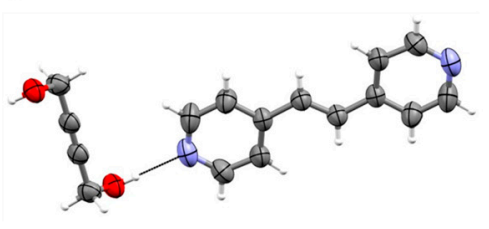

(b)

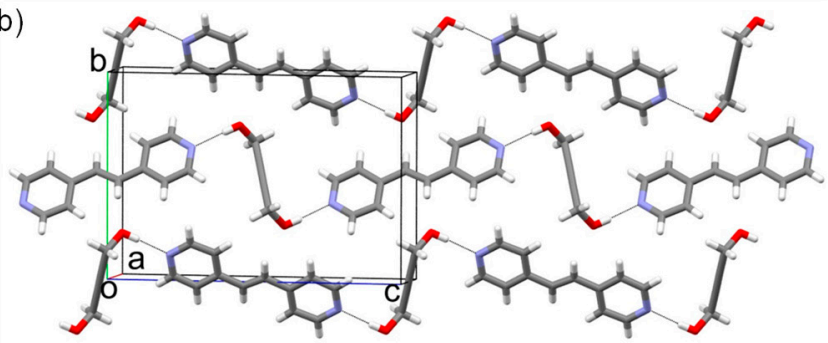

(d)

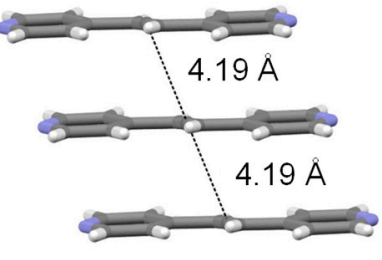

(c)

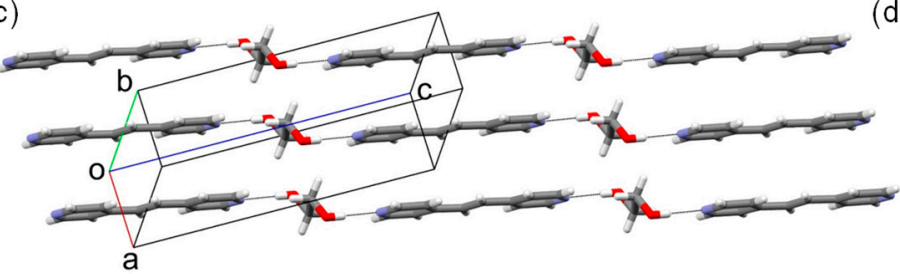

Figure 1. X-ray structure $\left[(\mathbf{1}, \mathbf{4}-\mathbf{b d}) \cdot\left(\mathbf{4}, \mathbf{4}^{\prime}-\mathbf{b p e}\right)\right]_{\mathrm{n}}$ : (a) ORTEP representation, (b) $1 \mathrm{D}$ hydrogen-bonded chains, (c) stacks of hydrogen-bonded chains, (d) stacked $C=C$ bonds of $4, \mathbf{4}^{\prime}$-bpe.

To determine photoreactivity of $\left[(\mathbf{1}, \mathbf{4}-\mathbf{b d}) \cdot\left(\mathbf{4}, \mathbf{4}^{\prime}-\mathbf{b p e}\right)\right]_{\mathrm{n}}$, a finely-ground crystalline powder was distributed between two glass plates and exposed to UV-irradiation ( $450 \mathrm{~W}$ medium-pressure $\mathrm{Hg}$ lamp) for a period of $55 \mathrm{~h}$. A ${ }^{1} \mathrm{H}-\mathrm{NMR}$ spectrum revealed the emergence of a single cyclobutane resonance (4.68 ppm) consistent with rctt-tetrakis (4-pyridyl) cyclobutane (4,4-tpcb) (79\% conversion), which was accompanied by a decrease in intensity of the olefinic signals (see Figure S2). Prolonged 
UV exposure did not result in an increase in conversion of olefin to cyclobutane. We also note that the amount of 1,4-bd present in the sample decreased by $6 \%$ during the photoreaction. We ascribe the decrease in 1,4-bd to sublimation of the diol, which may also affect the overall photoconversion. Indeed, we have determined that $\mathbf{1 , 4 - b d}$ as a pure form sublimes at $40-45^{\circ} \mathrm{C}$ at ambient pressure. Sublimation of 1,4-bd from the unreacted cocrystal, however, does not occur (see Experimental). We note that Groeneman has recently reported that the template 1,2-dibromo-4,5-diflorobenzene can be sublimed for product purification [7]. We confirmed the stereochemistry of the photoproduct generated from $\left[(\mathbf{1}, \mathbf{4}-\mathbf{b d}) \cdot\left(\mathbf{4}, \mathbf{4}^{\prime} \text {-bpe }\right)\right]_{\mathrm{n}}$ by treatment of acid and extraction into chloroform (see Figure S3) [8].

\subsection{Photoreactive Cocrystals of $\left[(\mathbf{1}, \mathbf{4}-\mathbf{b d}) \cdot\left(\mathbf{3}, \mathbf{3}^{\prime}-\mathbf{b} \mathbf{p e}\right)\right]_{\mathrm{n}}$}

Cocrystals of $\left[(\mathbf{1}, \mathbf{4} \text {-bd }) \cdot\left(\mathbf{3}, \mathbf{3}^{\prime} \text {-bpe }\right)\right]_{n}$ were obtained by dissolving equimolar $\mathbf{3}, \mathbf{3}^{\prime}$-bpe and $\mathbf{1}, \mathbf{4}$-bd in minimal boiling diethyl ether. The solvent was allowed to slowly evaporate for $2 \mathrm{~d}$ to yield colorless single crystals of $\left[(\mathbf{1}, \mathbf{4}-\mathbf{b d}) \cdot\left(3,3^{\prime}-\mathbf{b p e}\right)\right]_{\mathrm{n}}$. In contrast to $\left[(\mathbf{1}, \mathbf{4}-\mathbf{b d}) \cdot\left(\mathbf{4}, \mathbf{4}^{\prime}-\mathrm{bpe}\right)\right]_{\mathrm{n}}$, the cocrystals $\left[(1,4-b d) \cdot\left(3,3^{\prime}-\mathbf{b p e}\right)\right]_{n}$ were determined to be highly deliquescent.

The components of $\left[(\mathbf{1}, \mathbf{4}-\mathbf{b d}) \cdot\left(\mathbf{3}, \mathbf{3}^{\prime} \text {-bpe }\right)\right]_{n}$ crystallize in the monoclinic space group $P 21 / n$ (Table 1 , Figure 2). Similar to $\left[(\mathbf{1}, \mathbf{4}-\mathbf{b d}) \cdot\left(\mathbf{4}, \mathbf{4}^{\prime}-\mathbf{b} \mathbf{p e}\right)\right]_{\mathrm{n}}$, the asymmetric unit of $\left[(\mathbf{1}, \mathbf{4}-\mathbf{b d}) \cdot\left(\mathbf{3}, \mathbf{3}^{\prime}-\mathbf{b} \mathbf{p e}\right)\right]_{\mathrm{n}}$ consists of one half of a molecule of 1,4-bd and 3,3'-bpe. The components assemble via O-H $\cdots \mathrm{N}$ hydrogen bonds $[\mathrm{O}(1) \cdots \mathrm{N}(2)$ separation $(\AA): 2.802(1)]$ to form infinite 1D hydrogen-bonded chains along the crystallographic $c$-axis. The hydroxyl groups of $\mathbf{1}, \mathbf{4}-\mathbf{b d}$ also adopt an anti-conformation with a dihedral angle of nearly $180^{\circ}$. Adjacent $1 \mathrm{D}$ chains are sustained by bifurcating $\mathrm{C}-\mathrm{H}$ (pyridine) $\cdots \mathrm{O}$ and $\mathrm{C}-\mathrm{H}($ alkene) $\cdots \mathrm{O}$ forces along the $a$-axis $[\mathrm{C} \cdots \mathrm{O}$ separations $(\AA)$ : $\mathrm{C}(8) \cdots \mathrm{O}(1) 3.45, \mathrm{C}(5) \cdots \mathrm{O}(1) 3.56]$ such that neighboring chains lie offset and tilted by $61.6^{\circ}$. The hydrogen-bonded chains arrange into infinite offset 2D stacks along the $b$-axis such that the $\mathrm{C}=\mathrm{C}$ bonds lie parallel and separated by $4.21 \AA$.

(a)

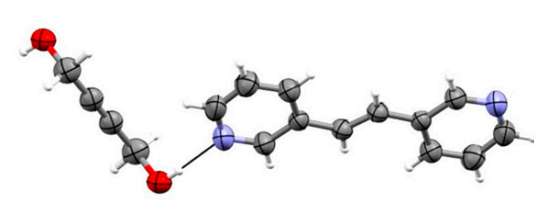

(b)

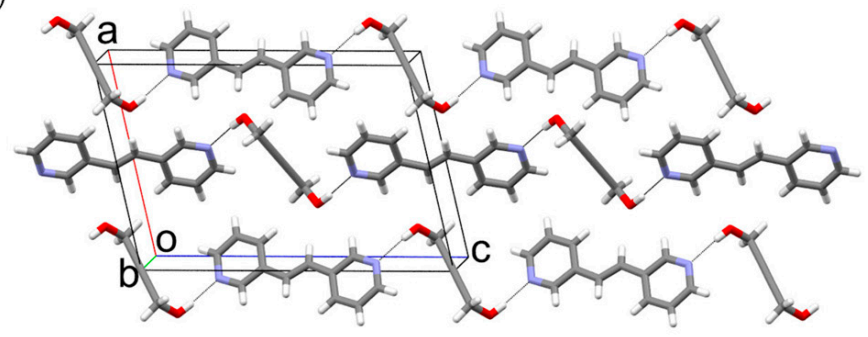

(c)

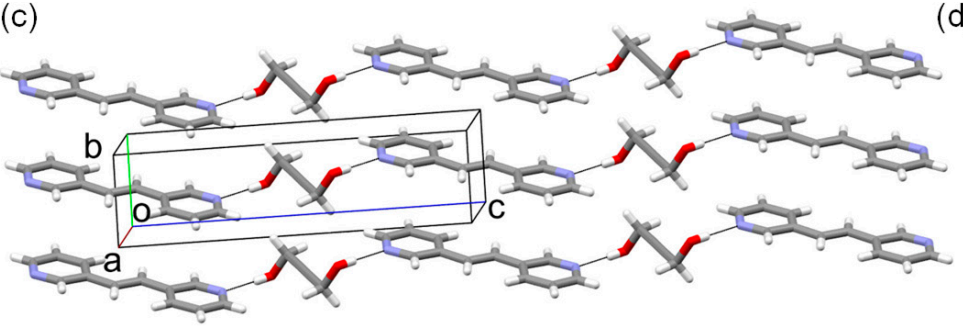

(d)

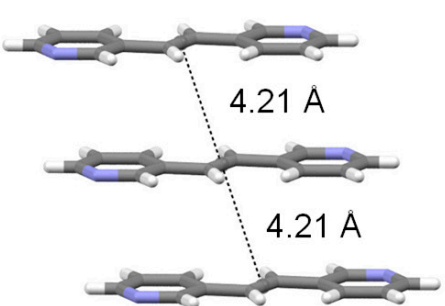

Figure 2. X-ray structure $\left[(\mathbf{1}, \mathbf{4}-\mathbf{b d}) \cdot\left(3, \mathbf{3}^{\prime} \text {-bpe }\right)\right]_{\mathrm{n}}$ : (a) ORTEP representation; (b) 1D chains; (c) stacks of hydrogen-bonded chains; (d) stacked $C=C$ bonds of 3, $3^{\prime}$-bpe.

When a finely-ground crystalline powder of $\left[(\mathbf{1}, \mathbf{4}-\mathbf{b d}) \cdot\left(3,3^{\prime}-\mathbf{b p e}\right)\right]_{\mathrm{n}}$ in a $20-\mathrm{mL}$ scintillation vial was exposed to UV-radiation for $23 \mathrm{~h}$, a ${ }^{1} \mathrm{H}-\mathrm{NMR}$ spectrum revealed $3,3^{\prime}$-bpe to be converted a cyclobutane product (68\% conversion) (see Figure S5). The formation of the photoproduct was evidenced by the emergence of a single cyclobutane resonance $(4.71 \mathrm{ppm})$ consistent with $r c t$-tetrakis (3-pyridyl) cyclobutane $\left(3,3^{\prime}-\mathbf{t p c b}\right)$ and a concomitant decrease in intensity of the olefinic resonances

The stereochemistry of the photoproduct $3,3^{\prime}$-tpcb as $r c t t$ - was confirmed by treatment with acid and extraction into chloroform (see Figure S6). Single crystals of $\left(r c t t-3,3^{\prime}-t p c b\right) \cdot\left(\mathrm{H}_{2} \mathrm{O}\right)$ in the form of plates were obtained by slow solvent evaporation over a period of $4 \mathrm{~d}$ in chloroform. 
The components of $\left(r c t t-3, \mathbf{3}^{\prime}\right.$-tpcb) $\cdot\left(\mathrm{H}_{2} \mathrm{O}\right)$ crystallize in the triclinic space group P $\overline{1}$ (Table 1$)$. The asymmetric unit consists of two unique one-half molecules of $r c t t-3, \mathbf{3}^{\prime}$-tpcb and one full molecule of $\mathrm{H}_{2} \mathrm{O}$. One cyclobutane (N3/N4) lies disordered over two positions (occupancies C17A/C17B 70/30). The transoid-pyridyl groups of the cyclobutanes adopt anti- (N1/N2) and syn-conformations (N3/N4) (Figure 3). The components of the solid assemble via $\mathrm{O}-\mathrm{H} \cdots \mathrm{N}$ hydrogen bonds [O $\cdots \mathrm{N}$ separations $(\AA): 2.926(6) \mathrm{O}(1) / \mathrm{N}(1), 2.839(5) \mathrm{O}(1) / \mathrm{N}(3)$ ] with the included water molecules bridging adjacent cyclobutanes. As a consequence of the assembly process, the components form 1D hydrogen-bonded chains along the crystallographic $b$-axis. Adjacent 1D chains stack along the $a$-axis and interact via edge-to-face $\mathrm{C}-\mathrm{H} \cdots \pi$ contacts to form $2 \mathrm{D}$ sheets. The $2 \mathrm{D}$ sheets interdigitate perpendicular to the $c$-axis.

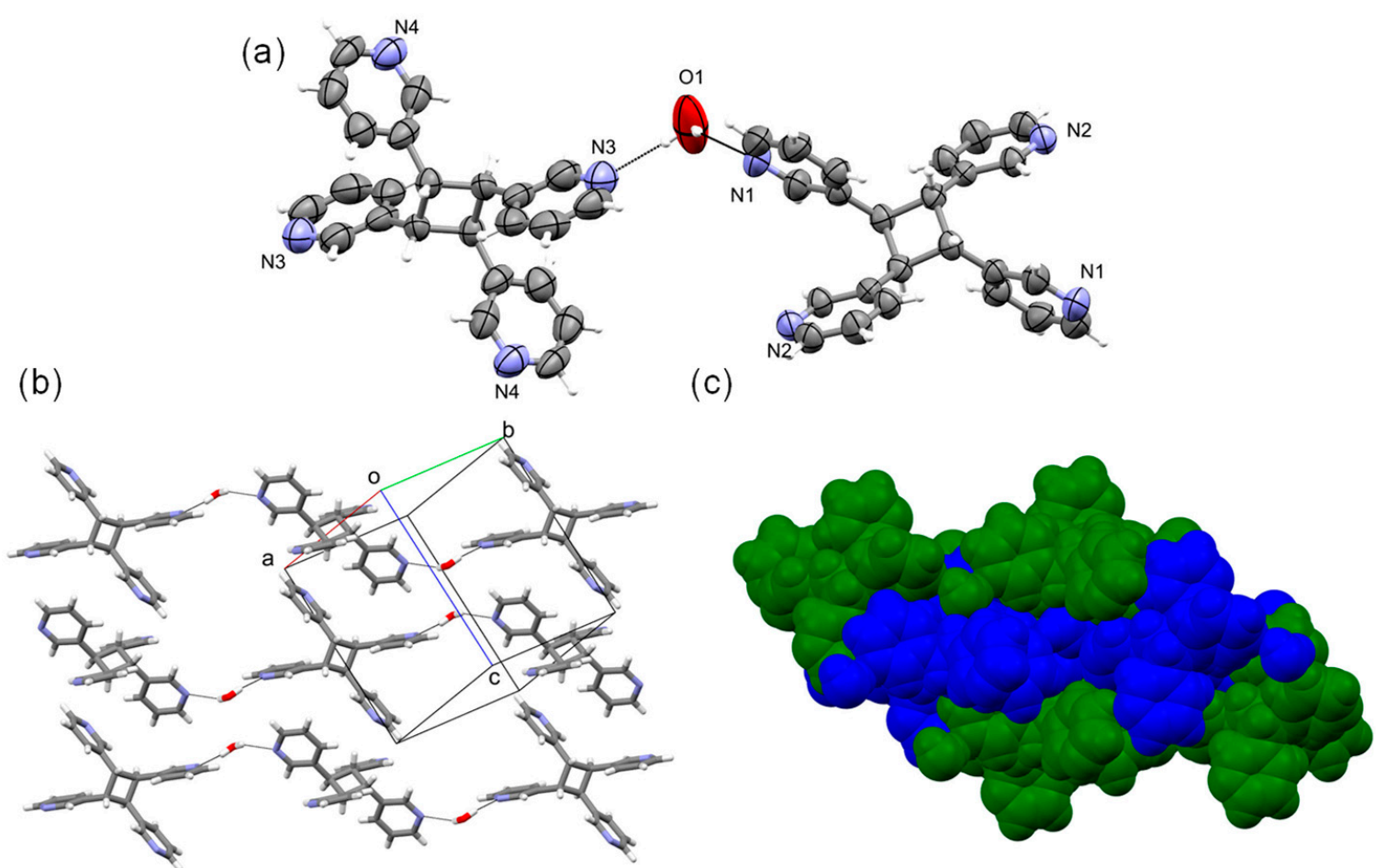

Figure 3. X-ray structure $\left(r c t t-3,3^{\prime}\right.$-tpcb) $\cdot\left(\mathrm{H}_{2} \mathrm{O}\right)$ : (a) ORTEP representation; (b) 1D hydrogen-bonded chains (c) interdigitated 2D sheets with separate 2D sheets blue and green.

\subsection{Mechanochemistry and Supramolecular Catalysis}

The diol 1,4-bd acts as a supramolecular catalyst to form $4,4^{\prime}$-tpcb in near quantitative yield. Specifically, dry-grinding of equimolar 1,4-bd and 4, $\mathbf{4}^{\prime}$-bpe using an agate mortar and pestle generated the cocrystal $\left[(\mathbf{1}, \mathbf{4}-\mathbf{b d}) \cdot\left(\mathbf{4}, \mathbf{4}^{\prime} \text {-bpe) }\right]_{\mathrm{n}}\right.$ in $20 \mathrm{~min}$ (see Figure S8). Moreover, cycles (5 cycles) of mechanical grinding followed by exposure to UV-radiation $(20 \mathrm{~h})$ with $50 \%$ loading of 1,4-bd resulted in near quantitative (95\%) conversion of $\mathbf{4}, \mathbf{4}^{\prime}$ - bpe to $\mathbf{4}, \mathbf{4}^{\prime}$ - $\mathbf{t p c b}$ (Figure 4, see Figure S9). Similar results were obtained for $20 \%$ loading of $\mathbf{1 , 4}$-bd, albeit with lower (34\%) conversion. ${ }^{1} \mathrm{H}-\mathrm{NMR}$ assay suggested 1,4-bd to sublime under the mechanochemical conditions in both cases (see Figure S10) [7]. PXRD data was consistent with crystalline $\left[(\mathbf{1}, \mathbf{4}-\mathbf{b d}) \cdot\left(\mathbf{4}, \mathbf{4}^{\prime}-\mathbf{b p e}\right)\right]_{\mathrm{n}}$ and $\mathbf{4}, \mathbf{4}^{\prime}$-tpcb being generated during the catalysis and grinding (see Figure S11) [1].

Infinitely stacked $\mathrm{C}=\mathrm{C}$ bonds in the solid state will exhibit a maximum possible theoretical conversion owing to independent photodimerization events taking place [9-12] We envision that the increase in conversion of $4,4^{\prime}$-bpe to $4,4^{\prime}-\mathbf{t p c b}$ achieved by supramolecular catalysis relative to the stoichiometric cocrystal $\left[(\mathbf{1}, \mathbf{4}-\mathbf{b d}) \cdot\left(\mathbf{4}, \mathbf{4}^{\prime}-\mathbf{b} \mathbf{p e}\right)\right]_{\mathrm{n}}$ likely involves 'free' diol being available for recrystallization to support reactivity of the $\mathrm{C}=\mathrm{C}$ bonds between the 1D hydrogen-bonded chains. 


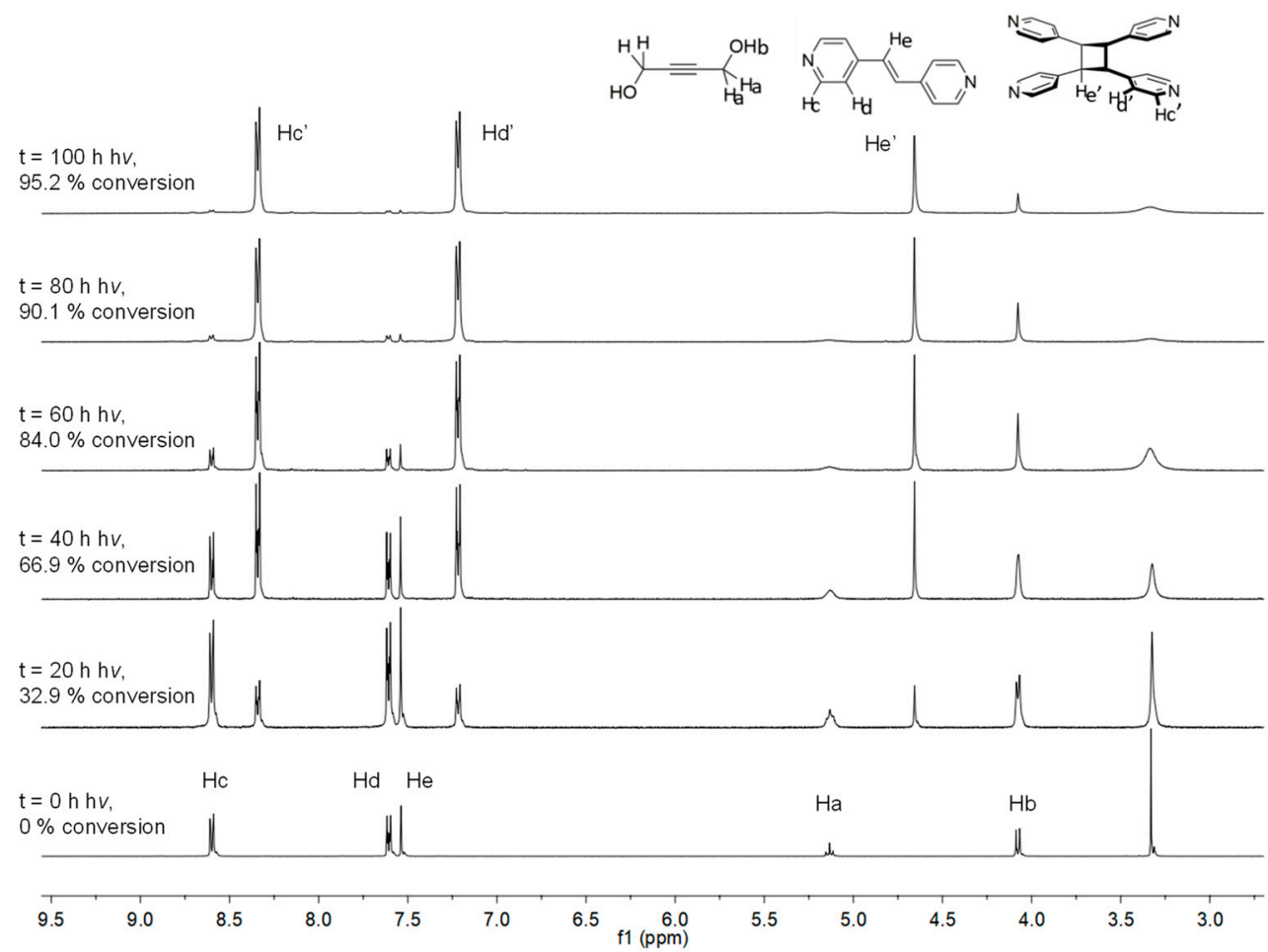

Figure 4. ${ }^{1} \mathrm{H}-\mathrm{NMR}$ spectra $\left(300 \mathrm{MHz}\right.$, DMSO- $\left.d_{6}\right)$ monitoring photoreactivity of $\left[(\mathbf{1}, \mathbf{4}-\mathbf{b d}) \cdot\left(\mathbf{4}, \mathbf{4}^{\prime}-\mathbf{b} \mathbf{p e}\right)\right]_{\mathrm{n}}$ at $50 \%$ catalyst loading of 1,4-bd (100 h UV exposure). UV-exposure time $(\mathrm{t})$ indicated with stacked spectra.

\section{Conclusions}

We have demonstrated 1,4-bd to function as a divergent template to direct $[2+2]$ photodimerizations in the solid state. Cocrystals containing 1,4-bd generate 1D hydrogen-bonded chains of $\left[(\mathbf{1}, \mathbf{4}-\mathbf{b d}) \cdot\left(n, n^{\prime} \text {-bpe) }\right]_{\mathrm{n}}\right.$ (where: $n=n^{\prime}=3$ or 4 ) that form infinite stacks. The cocrystals undergo [2+2] photodimerizations to form $r c t t-n, n^{\prime}-\operatorname{tpcb}\left(n=n^{\prime}=3\right.$ or 4$)$, with sublimation effects involving the template. An increase in yield of the photodimerization of $\left[(\mathbf{1}, \mathbf{4}-\mathbf{b d}) \cdot\left(\mathbf{4}, \mathbf{4}^{\prime}-\mathbf{b p e}\right)\right]_{\mathrm{n}}$ is realized with supramolecular catalysis. Our current efforts are focused to identify and apply approaches involving divergent templates to alkenes of increasing structural complexity.

\section{Materials and Methods}

\subsection{Materials}

Reagents 1,4-butynediol (1,4-bd) and trans-1,2-bis (4-pyridyl) ethylene $\left(\mathbf{4}, \mathbf{4}^{\prime}\right.$-bpe) were purchased from Sigma Aldrich ${ }^{\circledR}$ (St. Louis, MO, USA). Anhydrous diethyl ether $\left(\mathrm{Et}_{2} \mathrm{O}\right)$ and acetonitrile $(\mathrm{MeCN})$ were purchased from Fisher Scientific ${ }^{\mathrm{TM}}$ and VWR International ${ }^{\circledR}$, respectively. Chloroform $\left(\mathrm{CHCl}_{3}\right)$ and dichloromethane $\left(\mathrm{CH}_{2} \mathrm{Cl}_{2}\right)$ were purchased from Fischer Scientific ${ }^{\mathrm{TM}}$. All chemicals were used as received without further purification. The alkene trans-1,2-bis (3-pyridyl) ethylene (3, $\mathbf{3}^{\prime}$-bpe) was synthesized via a Hiyama-Heck coupling of triethoxy(vinyl)silane and 3-bromopyridine [13].

\subsection{Cocrystallizations}

Cocrystals of $\left[(\mathbf{1}, \mathbf{4}-\mathbf{b d}) \cdot\left(\mathbf{4}, \mathbf{4}^{\prime} \text {-bpe }\right)\right]_{n}$ were obtained by dissolving equimolar $\mathbf{4}, \mathbf{4}^{\prime}$-bpe (346 $\mathrm{mg}$, $2.0 \mathrm{mmol})$ and 1,4-bd (172 $\mathrm{mg}, 2.0 \mathrm{mmol})$ separately in $\mathrm{MeCN}(10 \mathrm{~mL})$. The two solutions were combined and the solvent was allowed to slowly evaporate for $6 \mathrm{~d}$ to yield colorless plate-like crystals of $\left[(\mathbf{1}, \mathbf{4}-\mathbf{b d}) \cdot\left(\mathbf{4}, \mathbf{4}^{\prime} \text {-bpe }\right)\right]_{\mathrm{n}}$ suitable for single-crystal X-ray diffraction (SCXRD). ${ }^{1} \mathrm{H}-\mathrm{NMR}(300 \mathrm{MHz}$, DMSO- $\left.d_{6}\right): \delta 8.60(\mathrm{dd}, J=4.5,1.6 \mathrm{~Hz}, 2 \mathrm{H}), 7.61(\mathrm{dd}, J=4.5,1.6 \mathrm{~Hz}, 2 \mathrm{H}), 7.55(\mathrm{~s}, 1 \mathrm{H}), 5.29-5.02(\mathrm{~m}, 1 \mathrm{H})$, $4.22-3.95(\mathrm{~m}, 2 \mathrm{H})$. 
For synthesis of $\left[(\mathbf{1}, \mathbf{4}-\mathbf{b d}) \cdot\left(\mathbf{3}, \mathbf{3}^{\prime} \text {-bpe }\right)\right]_{\mathrm{n}}$, equimolar 3,3'-bpe $(39 \mathrm{mg}, 0.2 \mathrm{mmol})$ and $\mathbf{1}, \mathbf{4}-\mathbf{b d}(19 \mathrm{mg}$, $0.2 \mathrm{mmol}$ ) were dissolved together in minimum boiling $\mathrm{Et}_{2} \mathrm{O}$. The solvent was allowed to slowly evaporate for $2 \mathrm{~d}$ to yield colorless plate-like crystals of $\left[(\mathbf{1}, \mathbf{4}-\mathbf{b d}) \cdot\left(\mathbf{3}, \mathbf{3}^{\prime} \text {-bpe }\right)\right]_{\mathrm{n}}$ suitable for SCXRD. ${ }^{1} \mathrm{H}-\mathrm{NMR}\left(300 \mathrm{MHz}, \mathrm{DMSO}-d_{6}\right): \delta 8.79(\mathrm{~d}, J=2.2 \mathrm{~Hz}, 1 \mathrm{H}), 8.49(\mathrm{~d}, J=4.7 \mathrm{~Hz}, 1 \mathrm{H}), 8.07(\mathrm{~d}, J=8.0 \mathrm{~Hz}$, $1 \mathrm{H}), 7.43(\mathrm{~s}, 1 \mathrm{H}), 7.43(\mathrm{t}, J=4.8 \mathrm{~Hz}, 1 \mathrm{H}), 5.20-5.04(\mathrm{~m}, 1 \mathrm{H}), 4.08(\mathrm{dd}, J=5.9,0.7 \mathrm{~Hz}, 2 \mathrm{H})$. Cocrystals of $\left[(\mathbf{1}, \mathbf{4}-\mathbf{b d}) \cdot\left(3,3^{\prime} \text {-bpe }\right)\right]_{\mathrm{n}}$ were determined to be highly deliquescent.

\subsection{Photodimerization}

All single crystals were finely ground using a mortar and pestle and then spread thinly between a pair of Pyrex glass plates for $\left[(\mathbf{1}, \mathbf{4}-\mathbf{b d})\left(\mathbf{4}, \mathbf{4}^{\prime}-\mathbf{b} \mathbf{p e}\right)\right]_{\mathrm{n}}$. Finely ground crystals of $\left[(\mathbf{1}, \mathbf{4}-\mathbf{b d})\left(\mathbf{3}, \mathbf{3}^{\prime}-\mathbf{b} \text { pe }\right)\right]_{\mathrm{n}}$ were thinly spread across the bottom of a $20-\mathrm{mL}$ glass scintillation vial. The samples were irradiated in $12 \mathrm{~h}$ intervals (ACE Glass photochemistry cabinet, $450 \mathrm{~W}$, medium-pressure Hg-vapor lamp). Cyclobutane formation was monitored using ${ }^{1} \mathrm{H}-\mathrm{NMR}$ spectroscopic assay.

\subsection{Photoproduct Isolation}

A photoreacted solid of $\left[(\mathbf{1}, \mathbf{4}-\mathbf{b d}) \cdot\left(\mathbf{4}, \mathbf{4}^{\prime}-\mathbf{b p e}\right)\right]_{\mathrm{n}}$ was dissolved in $3 \mathrm{M} \mathrm{HCl}$ and subsequently washed with $\mathrm{CH}_{2} \mathrm{Cl}_{2}(3 \times 15 \mathrm{~mL})$. The photoproduct was precipitated from the aqueous solution using $50 \%$ $\mathrm{NaOH}$ to $\mathrm{pH} 12$ and extracted with $\mathrm{CHCl}_{3}(3 \times 15 \mathrm{~mL})$. The organic layer was dried $\left(\mathrm{Na}_{2} \mathrm{SO}_{4}\right)$ and discoloration was removed using activated carbon. The solution was filtered and solvent was removed under vacuum to yield rctt-tetrakis (4-pyridyl) cyclobutane ( $r c t t-4,4-t p c b)$ [8]. ${ }^{1} \mathrm{H}-\mathrm{NMR}(300 \mathrm{MHz}$, DMSO- $\left.d_{6}\right): \delta 8.34(\mathrm{dd}, J=4.5,1.5 \mathrm{~Hz}, 2 \mathrm{H}), 7.22(\mathrm{dd}, J=4.5,1.6 \mathrm{~Hz}, 2 \mathrm{H}), 4.66(\mathrm{~s}, 1 \mathrm{H})$.

A photoreacted solid of $\left[(\mathbf{1}, \mathbf{4}-\mathbf{b d}) \cdot\left(\mathbf{3}, \mathbf{3}^{\prime} \text {-bpe }\right)\right]_{\mathrm{n}}$ was dissolved in $3 \mathrm{M} \mathrm{HCl}$ and subsequently washed with $\mathrm{CH}_{2} \mathrm{Cl}_{2}(3 \times 15 \mathrm{~mL})$. The photoproduct was precipitated from the aqueous solution using $50 \%$ $\mathrm{NaOH}$ to $\mathrm{pH} 11$ and extracted with $\mathrm{CHCl}_{3}(3 \times 15 \mathrm{~mL})$. The organic layer was dried $\left(\mathrm{Na}_{2} \mathrm{SO}_{4}\right)$. The solution was filtered and solvent evaporated under vacuum. The crude product was purified using flash column chromatography. The column was primed with $10 \% \mathrm{MeOH} / \mathrm{CH}_{2} \mathrm{Cl}_{2}$. The percentage of $\mathrm{MeOH}$ in $\mathrm{CH}_{2} \mathrm{Cl}_{2}$ was increased in $2 \%$ increments until pure photoproduct was collected. Fractions containing photoproduct were combined and solvent was removed under vacuum to yield rctt-tetrakis (3-pyridyl) cyclobutane (rctt-3,3-tpcb). ${ }^{1} \mathrm{H}-\mathrm{NMR}\left(300 \mathrm{MHz}, \mathrm{CDCl}_{3}\right): \delta 8.37$ (d, J = 2.1 Hz, 1H), 8.31 (dd, $J=4.8,1.4 \mathrm{~Hz}, 1 \mathrm{H}), 7.42-7.30(\mathrm{~m}, 1 \mathrm{H}), 7.06(\mathrm{dd}, J=7.9,4.8 \mathrm{~Hz}, 1 \mathrm{H}), 4.52(\mathrm{~s}, 1 \mathrm{H})$.

\subsection{X-ray Diffraction Experiments}

Diffraction data were collected on a Bruker ${ }^{\complement}$ Nonius $^{\circledR}$ (Billerica, MA, USA) APEX II Kappa single-crystal X-ray diffractometer at room temperature (298.15 K) using graphite-monochromated Mo $\mathrm{K} \alpha_{1}$ radiation $(\lambda=0.71073 \AA)$. Structure solution and refinement were accomplished using ShelXT [14] and ShelXL [15], respectively, in the Olex2 user graphical interface. The structures were solved using direct methods. All non-hydrogen atoms were identified from the difference Fourier map and refined anisotropically. All hydrogen atoms were placed in their calculated positions and were refined using isotropic thermal parameters.

All powder samples were mounted on glass slides. Each sample was finely ground using an agate mortar and pestle prior to mounting. PXRD data were collected by a Siemens D5000 X-ray diffractometer using $\mathrm{Cu} \mathrm{K} \alpha_{1}$ radiation $(\lambda=1.54056 \AA$ ) (scan type: locked coupled; scan mode: continuous; step size: $\left.0.02^{\circ}\right)$. PXRD data of $\left(r c t t-3,3^{\prime}-\mathbf{t p c b}\right) \cdot\left(\mathrm{H}_{2} \mathrm{O}\right)$ were collected at room temperature on a Bruker D8 Advance X-ray diffractometer. Instrument parameters: radiation wavelength, $\mathrm{Cu} \mathrm{K} \alpha_{1}$ $\left(\lambda=1.5418 \AA\right.$ ) ; scan type, coupled 2Theta/Theta; scan mode, continuous PSD fast; scan range, $5-40^{\circ}$ two-theta; step size, $0.02^{\circ}$; voltage, $40 \mathrm{kV}$; current, $30 \mathrm{~mA}$. Background subtractions were applied to all experimentally collected data within the Bruker ${ }^{\circledR}$ DIFFRAC.EVA v3.1 software suite. 


\subsection{H-NMR Experiments}

All ${ }^{1} \mathrm{H}-\mathrm{NMR}$ spectra were obtained on a Bruker ${ }^{\complement}$ Fourier-300 NMR spectrometer (Billerica, MA, USA) operating at $300 \mathrm{MHz}$. All data were processed with the MestReNova ${ }^{\mathrm{TM}}$ v6.0.2 software program.

\subsection{Mechanochemistry and Catalysis}

Cocrystals of $\left[(\mathbf{1}, \mathbf{4}-\mathbf{b d}) \cdot\left(\mathbf{4}, \mathbf{4}^{\prime}-\mathbf{b p e}\right)\right]_{\mathrm{n}}$ were generated by combining 1,4-bd $(21.9 \mathrm{mg}, 0.3 \mathrm{mmol})$ and $\mathbf{4}, \mathbf{4}^{\prime}$-bpe $(48.8 \mathrm{mg}, 0.3 \mathrm{mmol})$ and grinding in agate mortar and pestle for $12 \mathrm{~min}$. Cocrystals of [(1,4-bd) $\cdot\left(\mathbf{3}, \mathbf{3}^{\prime}\right.$-bpe $\left.)\right]_{\mathrm{n}}$ were generated by combining $\mathbf{1}, \mathbf{4}-\mathbf{b d}(48.7 \mathrm{mg}, 0.6 \mathrm{mmol})$ and $\mathbf{3}, \mathbf{3}^{\prime}$-bpe $(101.6 \mathrm{mg}$, $0.6 \mathrm{mmol}$ ) together and grinding in an agate mortar and pestle for $30 \mathrm{~min}$. The resulting crystalline phases were confirmed using powder X-ray diffraction (PXRD).

For catalysis employing a 1,4-bd template, $4, \mathbf{4}^{\prime}$-bpe $(116 \mathrm{mg}, 0.64 \mathrm{mmol})$ with 50 or $20 \mathrm{~mol} . \%$ of 1,4-bd were combined and finely ground using an agate mortar and pestle. The formation of cocrystalline material was confirmed using PXRD. The finely ground crystalline powders were spread thinly between two glass plates and exposed to broadband UV-irradiation. The crystalline materials were exposed to additional dry grinding ( $20 \mathrm{~min}$ in an agate mortar and pestle) after $20 \mathrm{~h}$ intervals of UV-irradiation. Solid-state catalysis reactions were monitored using ${ }^{1} \mathrm{H}-\mathrm{NMR}$ spectroscopy and PXRD.

\subsection{Sublimation Experiments}

A crystalline sample of 1,4-bd (see ref. [16] for crystal structure) was placed in a glass sublimation apparatus. The apparatus was gently heated to ca. $40^{\circ} \mathrm{C}$ and the temperature was maintained for $12 \mathrm{~h}$. The sublimed material was confirmed to be $\mathbf{1 , 4 - b d}$ by ${ }^{1} \mathrm{H}-\mathrm{NMR}$ spectroscopic analysis (see Figure S12). ${ }^{1} \mathrm{H}-\mathrm{NMR}\left(300 \mathrm{MHz}, \mathrm{CDCl}_{3}\right): \delta 4.34(\mathrm{~s}, 4 \mathrm{H})$.

Supplementary Materials: The following are available online. Figure S1. ${ }^{1} \mathrm{H}-\mathrm{NMR}\left(300 \mathrm{MHz}, \mathrm{DMSO}-d_{6}\right)$ spectrum of cocrystal $\left[(\mathbf{1}, \mathbf{4}-\mathbf{b d}) \cdot\left(\mathbf{4}, \mathbf{4}^{\prime} \text {-bpe }\right)\right]_{n} ;$ Figure S2. ${ }^{1} \mathrm{H}-\mathrm{NMR}\left(300 \mathrm{MHz}\right.$, DMSO- $\left.d_{6}\right)$ spectrum of cocrystal $\left[(\mathbf{1}, \mathbf{4}-\mathbf{b d}) \cdot\left(\mathbf{4}, \mathbf{4}^{\prime} \text {-bpe }\right)\right]_{\mathrm{n}}$ following $55 \mathrm{~h}$ of UV exposure; Figure S3. ${ }^{1} \mathrm{H}-\mathrm{NMR}\left(300 \mathrm{MHz}\right.$, DMSO- $\left.d_{6}\right)$ spectrum of isolated $r c t t-4,4^{\prime}$-tpcb from $\left[(\mathbf{1}, \mathbf{4}-\mathbf{b d}) \cdot\left(\mathbf{4}, \mathbf{4}^{\prime}-\mathbf{b p e}\right)\right]_{\mathrm{n}}$; Figure S4. ${ }^{1} \mathrm{H}-\mathrm{NMR}\left(300 \mathrm{MHz}\right.$, DMSO- $\left.d_{6}\right)$ spectrum of cocrystal $\left[(\mathbf{1}, \mathbf{4}-\mathbf{b d}) \cdot\left(\mathbf{3}, \mathbf{3}^{\prime} \text {-bpe }\right)\right]_{n} ;$ Figure S5. ${ }^{1} \mathrm{H}-\mathrm{NMR}\left(300 \mathrm{MHz}, \mathrm{DMSO}-d_{6}\right)$ spectrum of $\left[(\mathbf{1}, \mathbf{4}-\mathbf{b d}) \cdot\left(\mathbf{3}, \mathbf{3}^{\prime} \text {-bpe }\right)\right]_{\mathrm{n}}$ following $23 \mathrm{~h}$ of UV exposure.; Figure $\mathrm{S} 6 .{ }^{1} \mathrm{H}-\mathrm{NMR}\left(300 \mathrm{MHz}, \mathrm{CDCl}_{3}\right)$ spectrum of isolated $r c t t-3,3^{\prime}$-tpcb from $\left[(\mathbf{1}, 4-\mathbf{b d}) \cdot\left(3,3^{\prime} \text {-bpe }\right)\right]_{n}$; Figure S7. Powder X-ray diffractogram of $\left(r c t t-3,3^{\prime}-\right.$ tpcb) $) \cdot\left(\mathrm{H}_{2} \mathrm{O}\right)($ top, blue) compared to the simulated pattern generated from single-crystal X-ray data (bottom, black); Figure S8. Powder X-ray diffractograms of $\left[(\mathbf{1}, \mathbf{4}-\mathbf{b d}) \cdot\left(\mathbf{4}, \mathbf{4}^{\prime} \text {-bpe }\right)\right]_{n}$ generated through dry grinding (top, black) compared to simulated from single-crystal X-ray diffraction data (blue). Simulated patterns of pure 1,4-bd and 4,4-bpe reproduced from TELXAJ and AZSTBB, respectively; Figure S9. Powder X-ray diffractograms at 50\% catalyst loading of 1,4-bd to generate $\left[(\mathbf{1}, \mathbf{4}-\mathbf{b d}) \cdot\left(\mathbf{4}, \mathbf{4}^{\prime} \text {-bpe }\right)\right]_{\mathrm{n}}$ (top, blue) compared to the simulated patters of $\mathbf{1}, \mathbf{4}-\mathbf{b d}$ (middle, black) and $\left[(1,4-b d) \cdot\left(4,4^{\prime}-\text { bpe }\right)\right]_{n}$ (bottom, black). Simulated pattern of pure 1,4-bd reproduced from TELXAJ; Figure S10. ${ }^{1} \mathrm{H}-\mathrm{NMR}\left(300 \mathrm{MHz}\right.$, DMSO- $\left.d_{6}\right)$ spectra monitoring the photoreactivity of $\left[(\mathbf{1}, \mathbf{4}-\mathbf{b d}) \cdot\left(\mathbf{4}, \mathbf{4}^{\prime}-\mathbf{b p e}\right)\right]_{\mathrm{n}}$ at $20 \mathrm{~mol} . \%$ catalyst loading of 1,4-bd over $100 \mathrm{~h}$ of UV exposure. Total UV-exposure time (t) indicated with each-NMR; Figure S11.

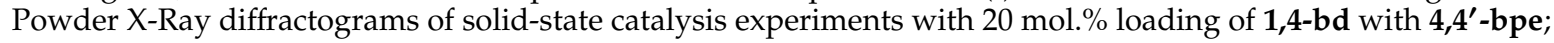
and Figure S12. ${ }^{1} \mathrm{H}-\mathrm{NMR}\left(300 \mathrm{MHz}, \mathrm{CDCl}_{3}\right)$ spectrum of sublimed 1,4-bd.

Author Contributions: conceptualization, S.M.O. and L.R.M.; methodology, S.M.O. and J.Q.; formal analysis, S.M.O., J.Q. and L.R.M.; investigation, S.M.O., J.Q. and L.R.M.; resources, L.R.M.; data curation, S.M.O. and J.Q.; writing-original draft preparation, S.M.O. and L.R.M.; writing—review and editing, S.M.O., J.Q. and L.R.M.; supervision, L.R.M.; funding acquisition, L.R.M.

Acknowledgments: The National Science Foundation (L.R.M. DMR-1708673) is acknowledged for support of the work.

Conflicts of Interest: The authors declare no conflict of interest.

\section{References}

1. Sokolov, A.N.; Bučar, D.-K.; Baltrusaitis, J.; Gu, S.X.; MacGillivray, L.R. Supramolecular catalysis in the organic solid state through dry brinding. Angew. Chem. Int. Ed. 2010, 49, 4273-4277. [CrossRef] [PubMed] 
2. Stojakovic, J.; Farris, B.S.; MacGillivray, L.R. Vortex grinding for mechanochemistry: Application for automated supramolecular catalysis and preparation of a metal-organic framework. Chem. Commun. 2012, 48, 7958-7960. [CrossRef] [PubMed]

3. Campillo-Alvarado, G.; Brannan, A.D.; Swenson, D.C.; MacGillivray, L.R. Exploiting the hydrogen-bonding capacity of organoboronic acids to direct covalent bond formation in the solid state: Templation and catalysis of the [2 + 2] photodimerization. Org. Lett. 2018, 20, 5490-5492. [CrossRef] [PubMed]

4. Toda, F.; Tanaka, K.; Sekikawa, A. Host-guest complex formation by a solid-solid reaction. J. Chem. Soc. Chem. Commun. 1987, 279-280. [CrossRef]

5. Toda, F. Reaction control by a host-guest complexation method. J. Inclus. Phenom. Mol. Recognit. Chem. 1989, 7, 247-256. [CrossRef]

6. Schmidt, G.M.J. Photodimerization in the solid state. Pure Appl. Chem. 1971, 27, 647-678. [CrossRef]

7. Grobelny, A.L.; Verdu, F.A.; Groeneman, R.H. Solvent-free synthesis and purification of a photoproduct via sublimation of a tetrahalogenated template. CrystEngComm 2017, 19, 3562-3565. [CrossRef]

8. MacGillivray, L.R.; Reid, J.L.; Ripmeester, J.A. Supramolecular control of reactivity in the solid state using linear molecular templates. J. Am. Chem. Soc. 2000, 122, 7817-7818. [CrossRef]

9. Desiraju, G.; Kannan, V. What is the maximum yield in the solid state cinnamic acid dimerisation? A combinatorial mathematical approach. J. Chem. Sci. 1986, 96, 351-362. [CrossRef]

10. Even, J.; Bertault, M. Monte-Carlo simulations of chemical reactions in molecular crystals. J. Chem. Phys. 1999, 110, 1087-1096. [CrossRef]

11. Harris, K.D.M.; Thomas, J.M.; Williams, D. Mathematical analysis of intra-stack dimerizations in reactive crystalline solids. J. Chem. Soc. Faraday Trans. 1991, 87, 325-331. [CrossRef]

12. Chanthapally, A.; Oha, W.T.; Vittal, J.J. [2 + 2] Cycloaddition reaction as a tool to monitor the formation of thermodynamically stable ladder coordination polymers. CrystEngComm 2013, 15, 9324-9327. [CrossRef]

13. Gordillo, A.; Ortuño, M.A.; López-Mardomingo, C.; Lledós, A.; Ujaque, G.; de Jesús, E. Mechanistic studies on the Pd-catalyzed vinylation of aryl halides with vinylalkoxysilanes in water: The effect of the solvent and $\mathrm{NaOH}$ promoter. J. Am. Chem. Soc. 2013, 135, 13749-13763. [CrossRef] [PubMed]

14. Sheldrick, G. ShelXT-Integrated space-group and crystal-structure determination. Acta Crystallogr. Sect. A 2015, 71, 3-8. [CrossRef] [PubMed]

15. Sheldrick, G. Crystal structure refinement with ShelXL. Acta Crystallogr. Sect. C 2015, 71, 3-8. [CrossRef] [PubMed]

16. Steiner, T. 2-Butyne-1,4-diol. Acta Crystallogr. Sec. C 1996, 52, 2885-2887. [CrossRef]

Sample Availability: Samples of the compounds are not available from the authors.

(C) 2019 by the authors. Licensee MDPI, Basel, Switzerland. This article is an open access article distributed under the terms and conditions of the Creative Commons Attribution (CC BY) license (http://creativecommons.org/licenses/by/4.0/). 